\title{
The assessment of carotid intima media thickness and serum Paraoxonase-1 activity in Helicobacter pylori positive subjects
}

Halide S Akbas ${ }^{*}$, Sebahat Basyigit ${ }^{2}$, Inci Suleymanlar ${ }^{3}$, Didem Kemaloglu ${ }^{4}$, Serkan Koc ${ }^{4}$, Fatih Davran ${ }^{1}$, Ibrahim Demir ${ }^{4}$, Gultekin Suleymanlar ${ }^{2}$

\begin{abstract}
Background: The role of inflammation in the pathogenesis and progression of atherosclerosis has been increasingly discussed. Although the seroepidemiological studies have suggested a relationship between Helicobacter pylori (H. pylori) infection and atherosclerosis; the issue is still controversial. It is well known that abnormal lipid profil is related to atherosclerosis and the measurement of carotid-intima media thickness (CIMT) is one of the surrogate marker of atherosclerosis. The serum concentration of high-density lipoprotein (HDL-C) has been known to have an inverse correlation with the development of atherosclerosis. Paraoxonase-1 (PON1) is a major anti-atherosclerotic component of HDL-C. PON1 activity is related to lipid peroxidation and prospective cardiovascular risk. The aim of this study was to investigate CIMT and serum PON1 activities along with lipid parameters in $\mathrm{H}$. pylori positive and negative subjects.
\end{abstract}

Methods: Thirty H. pylori positive subjects and thirty-one negative subjects were enrolled. H. pylori infection was diagnosed by the presence of positivity of stool H. pylori antigen test or Carbon 14 labeled urea breath test. Serum PON1 activity was measured spectrophotometrically. Traditional cardiovascular risk factors were investigated and laboratory analysis included measurement of serum triglycerides (TG), total cholesterol (TC), high-density lipoprotein (HDL-C) and low-density lipoprotein cholesterol (LDL-C). We assessed CIMT by high-resolution ultrasound of both common carotid arteries.

Results: We found that the mean and maximum values of right and overall CIMT in $H$. pylori positive subjects were significantly thicker than those of $\mathrm{H}$. pylori negative subjects. There was no significant differences in serum HDL-C, LDL-C, TC levels and TC/HDL-C ratios between two groups. Serum TG levels of H. pylori positive subjects were significantly higher than those of $H$. pylori negative subjects $(p=0.014)$. We found that PON1 activities were significantly lower in $\mathrm{H}$. pylori positive subjects compared with negative subjects. No significantly correlation was observed between PON1 and CIMT values.

Conclusions: There is an increase in CIMT values in patients with $H$. pylori positive compared to $H$. pylori negative subjects. PON1 activity decrease significantly in $\mathrm{H}$. pylori positive subjects. However, an association between PON1 and CIMT was not found. These data indicated that H. pylori may have a role in atherosclerotic processes, however, further studies are needed to evaluate the exact mechanisms.

\footnotetext{
* Correspondence: halideakbas@akdeniz.edu.tr

${ }^{1}$ Akdeniz University Faculty of Medicine, Department of Biochemistry,

Antalya, Turkey

Full list of author information is available at the end of the article
} 


\section{Introduction}

Helicobacter pylori is a gram negative curved bacillus that is frequently found in the human stomach and causes chronic and active gastritis, peptic ulcer disease and is associated with gastric adenocarcinoma [1,2]. Several studies have demonstrated that $H$. pylori infection is also associated with the development of coronary atherosclerosis [3]. Atherosclerosis pathogenesis includes abnormal lipid metabolism, endothelial dysfunction, inflammatory and immunological factors, plaque rupture and smoking [4]. Infectious processes can contribute to the pathogenesis of atherosclerosis by producing chronic infection of the vessels with inflammation leading to endothelial dysfunction [5]. It has been suggested that exposure to sustained high levels of endotoxin constitute a risk factor for atherosclerosis in animal models and, likely, in humans $[5,6]$.

A low concentration of HDL-C is a well-known risk factor for coronary heart disease [5]. There are several well-documented functions of high plasma levels of HDL-C preventing the development of atherosclerosis. Most important function of HDL is to promote the efflux of cholesterol from cells. HDL-C also possesses antioxidant and antiinflammatory activities. The antioxidant activity of HDL-C is largely due to its paraoxonase-1 (PON1) content [7]. Human serum paraoxonase (PON1), a high-density lipoprotein (HDL)-bound ester hydrolase enzyme, has been shown to protect LDL from in vitro oxidation by hydrolysis of biologically active lipoperoxides [4]. Animal studies, including PON1knockout mouse, demonstrated that PON1 deficiency was shown to increase susceptibility to LDL oxidation and atherosclerosis development [8]. In humans, it has been suggested that PON1 is significantly associated with atherosclerotic risk. PON1 activity is geneticly regulated and varies widely among populations [9]. Previous studies have shown LDL oxidation and the degradation of PON1 activity were significantly correlated [10]. Although serum PON1 activity in patients with coronary heart disease is decrease and is negatively related to the severity of coronary artery lesions, the correlation between PON1 activity and CIMT is controversial $[11,12]$.

Existing cardiovascular diseases (CVDs) are found to be correlated with carotid artery intima-media thickness (CIMT) measured by ultrasound and are predictive of CVD in individuals without clinically evident disease. CIMT is now widely used as a early marker for atherosclerotic disease [13].

The aim of the present study was to evaluate the association between serum PON-1 activities and CIMT values in patients with $H$. pylori. For this purpose, we measured the CIMT and we compared the serum PON1 activity and blood lipids between $H$. pylori positive and negative subjects.

\section{Materials and methods \\ Patients}

This study was approved by institutional ethical committee of Akdeniz University, Faculty of Medicine. The subjects were selected among adults who visited the Department of Gastroenterology because of dyspeptic symptoms and were tested for $H$. pylori infection in Akdeniz University Hospital, between August and November 2009. H. pylori infection was identified by the presence of positivity of $H$. pylori stool antigen test or Carbon 14 labeled urea breath test. We excluded patients who had acute infectious, rheumatologic and cardiovascular disease. For the study we included $30 \mathrm{H}$. pylori infected individuals (14 male and 16 female). 31 healthy noninfected, (15 male and 16 female), age and sex matched individuals were enrolled in this study for a control. All subjects were informed about the study and the written consent was obtained. We obtained detailed medical history about smoking habits, the presence of diabetes mellitus, hypertension, hyperlipidemia, family history of cardiovascular.disease and medication including antihypertensive and antihyperlipidemic drugs. Blood pressure was measured with manual sphygmomanometer. Body mass index (BMI; $\mathrm{kg} / \mathrm{m}^{2}$ ) was calculated by dividing the body weight $(\mathrm{kg})$ with squared height $\left(\mathrm{m}^{2}\right)$. Their routine laboratory tests which contain complete blood count, serum glucose, creatinine and alanin aminotransferase (ALT) levels were recorded.

\section{Measurement of Serum Lipid and Lipoprotein Levels}

Venous blood samples were obtained following an overnight fasting state. Serum samples were separated and stored at $-80^{\circ} \mathrm{C}$ until the analysis. Serum total cholesterol (TC), HDL cholesterol (HDL-C) and triglyceride (TG) levels were measured with the enzymatic colorimetric method by using commercial kits on a Modular PPP auto-analyzer (Roche Diagnostics). Serum LDL-C levels were calculated by using Friedewald formula [14]. Serum TC/HDL-C ratio was also calculated. This ratio represents an atherogenic index, which is an important prognostic marker for cardiovascular disease [15].

\section{Measurement of Serum PON1 Activity}

Serum PON1 activity was measured by adding serum to Tris buffer $(100 \mathrm{mmol} / \mathrm{L}, \mathrm{pH} 8.0)$ containing $2 \mathrm{mmol} / \mathrm{L}$ $\mathrm{CaCl}_{2}$ and $5.5 \mathrm{mmol} / \mathrm{L}$ paraoxon $(\mathrm{O}, \mathrm{O}$-diethyl-Op-nitrophenylphosphate; Sigma Chemical Co). The rate of generation of p-nitrophenol was determined at $405 \mathrm{~nm}$. 
according to MacKness B et al. [16]. The method was applied to an automated analyzer (Syva V-Twin, Siemens Diagnostics). The results are expressed as $\mathbf{U} / \mathbf{L}$.

\section{Ultrasound Scanning Procedure}

Subjects were evaluated for carotid intima media thickness (CIMT) and plaque occurrence by using high resolution grey-scale Doppler ultrasonography. In a semidark room, all subject lay supine with their necks slightly hyperextended and rotated away from the imaging transducer. Both carotid arteries were scanned. CIMT was defined as the distance between the leading edge of the lumen intimal interface and the leading edge of the media adventitia interface of the far wall [13].

\section{Statistical Analysis}

Data analysis was done with a statistical software package (SPSS for Windows, Version 16.0, SPSS Inc, and Chicago, Ill). Quantitative data were expressed as mean $( \pm$ SD) or as medians. The comparisons of parameters were performed using Student's $t$-test. Correlation analyses were performed using Pearson's correlation test. A p-value of $<0.05$ was considered as significant.

\section{Results}

We included 30 subjects (14 male, 16 female) infected with $H$. pylori and 31 subjects ( 15 male, 16 female) without $H$. pylori infection. The demographic and clinical characteristics of study population are shown in Table 1 . There were no statistically significant differences between two groups with regard to demographic and clinical characteristics (age, gender, BMI, smoking habits; history of diabetes mellitus; hypertension; family history for CVD).

As shown in Table 2; serum TG levels were significantly higher in $\mathrm{H}$. pylori positive subjects than $\mathrm{H}$. pylori negative subjects $(1.81 \pm 0.79 \mathrm{mmol} / \mathrm{L}$ vs $1.32 \pm 0.73$ $\mathrm{mmol} / \mathrm{L}, \mathrm{p}<0.05)$. There were no statistically significant differences in TC, HDL-C, LDL-C levels and TC/HDL-C ratios between the two groups. Serum PON1 activity was significantly lower in $H$. pylori positive subjects when compared with negative subjects $(270.03 \pm 84.82$ vs $340.00 \pm 123.70 \mathrm{U} / \mathrm{L}, \mathrm{p}<0.05$ ).

Structural measurements of vessels for $H$. pylori positive and negative subjects at enrollment are shown in Table 3. Atherosclerotic plaques in the common carotid artery were shown in $1 \%$ (3 of 30) of $H$. pylori positive patients and only $0.3 \%$ ( 1 of 30$)$ of control subjects. The mean and maximum values of right CIMT were significantly increased in $H$. pylori positive subjects compared with negative subjects $(\mathrm{p}<0.05)$. The mean and maximum values of left CIMT were tend to be higher in subjects with $H$. pylori but the differences were not statistically significant between two groups. We calculated mean and maximum overall CIMT by using left and right CIMT measurements. The mean and maximum values of overall CIMT were significantly higher in $H$. pylori positive subjects than negative subjects $(\mathrm{p}<$ 0.05) (Table 3).

In $H$. pylori positive subjects, serum PON1 activities were significantly correlated with HDL-C $(\mathrm{r}=0.732, \mathrm{p}<$ $0.05)$, with TG $(\mathrm{r}=-0.689, \mathrm{p}<0.05)$ and TC/HDL-C ratio $(\mathrm{r}=-0.334, \mathrm{p}<0.05)$. Serum HDL-C levels were significantly correlated with mean $(\mathrm{r}=-0.348, \mathrm{p}<0.05)$ and maximum $(\mathrm{r}=-0.366, \mathrm{p}<0.05)$ right CIMT, mean $(\mathrm{r}=-0.403, \mathrm{p}<0.05)$ and maximum $(\mathrm{r}=-0.403, \mathrm{p}<$ $0.05)$ overall CIMT values while no correlation was found with mean and maximum left CIMT values ( $\mathrm{p}>$ 0.05). We did not found any significant correlation between PON1 and CIMT values.

In $H$. pylori negative subjects, serum PON1 activities were significantly correlated with TG $(r=-0.398$,

Table 1 Demographic and Clinical Characteristics of Helicobacter pylori positive and negative subjects

\begin{tabular}{lccc}
\hline Parameter & $\begin{array}{c}\text { H. } \text { pylori positive subjects } \\
(\mathbf{n}=\mathbf{3 0})\end{array}$ & $\begin{array}{c}\text { H. } \text { pylori negative subjects } \\
(\mathbf{n}=\mathbf{3 1})\end{array}$ & p value \\
\hline Age (years) & $40.9 \pm 10.3$ & $42.3 \pm 9.4$ & $\mathrm{NS}$ \\
\hline Gender M/F & $13 / 17$ & $14 / 16$ & $\mathrm{NS}$ \\
\hline DM & 1 & 4 & $\mathrm{NS}$ \\
\hline $\mathrm{HT}$ & 4 & 10 & $\mathrm{NS}$ \\
\hline $\mathrm{HPL}$ & 8 & 15 & $\mathrm{NS}$ \\
\hline Smoking & 12 & 4 & $\mathrm{NS}$ \\
\hline Family history of CVD & 3 & $121 \pm 8$ & $\mathrm{NS}$ \\
\hline Systolic BP $(\mathrm{mmHg})$ & $119 \pm 3$ & $79 \pm 6.6$ & $\mathrm{NS}$ \\
\hline Diastolic BP $(\mathrm{mmHg})$ & $78.5 \pm 8.8$ & $26.2 \pm 3.8$ & $\mathrm{NS}$ \\
\hline BMl $(\mathrm{kg} / \mathrm{m} 2)$ & $27.1 \pm 3.7$ & & $\mathrm{NS}$ \\
\hline
\end{tabular}

Results are expressed as mean \pm SD or number of patients.

Abbreviations: DM: diabetes mellitus, HT: hypertension, HPL: hyperlipidemia, CVD: cardiovascular disease, Systolic BP: systolic blood pressure, Diastolic BP: diastolic blood pressure. BMI: body mass index, NS: non-significant 
Table 2 Biochemical variables in Helicobacter pylori positive and negative subjects

\begin{tabular}{lccc}
\hline Parameter & $\begin{array}{c}\text { H. pylori positive subjects } \\
(\mathbf{n}=\mathbf{3 0})\end{array}$ & $\begin{array}{c}\text { H. pylori negative subjects } \\
\text { (n = 31) }\end{array}$ & p value \\
\hline $\mathrm{Hb}(\mathrm{g} / \mathrm{dL})$ & $13.6 \pm 1.8$ & $13.8 \pm 1.5$ & $\mathrm{NS}$ \\
\hline $\mathrm{WBC}\left(\times 10^{\prime} / \mathrm{L}\right)$ & $7.38 \pm 1.45$ & $7.56 \pm 1.98$ & $\mathrm{NS}$ \\
\hline $\mathrm{Glu}(\mathrm{mmol} / \mathrm{L})$ & $5.44 \pm 2.14$ & $4.95 \pm 0.67$ & $\mathrm{NS}$ \\
\hline $\mathrm{ALT}(\mathrm{U} / \mathrm{L})$ & $28.4 \pm 21$ & $25.6 \pm 23$ & $\mathrm{NS}$ \\
\hline $\mathrm{TC}(\mathrm{mmol} / \mathrm{L})$ & $4.47 \pm 1.32$ & $4.69 \pm 0.98$ & $\mathrm{NS}$ \\
\hline $\mathrm{LDL}-\mathrm{C}(\mathrm{mmol} / \mathrm{L})$ & $2.74 \pm 0.80$ & $2.84 \pm 0.77$ & $\mathrm{NS}$ \\
\hline $\mathrm{HDL}-\mathrm{C}(\mathrm{mmol} / \mathrm{L})$ & $1.15 \pm 0.30$ & $1.21 \pm 0.38$ & $\mathrm{NS}$ \\
\hline $\mathrm{TG}(\mathrm{mmol} / \mathrm{L})$ & $1.81 \pm 0.79$ & $1.32 \pm 0.73^{*}$ & $<0.05$ \\
\hline $\mathrm{Cr}(\mu \mathrm{mol} / \mathrm{L})$ & $63.64 \pm 13.26$ & $68.06 \pm 9.72$ & $\mathrm{NS}$ \\
\hline $\mathrm{TC} / \mathrm{HDL}-\mathrm{C}$ & $4.13 \pm 1.65$ & $4.27 \pm 1.95$ & $\mathrm{NS}$ \\
\hline $\mathrm{PON} 1(\mathrm{U} / \mathrm{L})$ & $270.03 \pm 84.82$ & $340.00 \pm 123.70^{*}$ & $<0.05$ \\
\hline
\end{tabular}

Abbreviations: Hb: Hemoglobin, WBC: White blood cell, Glu: Glucose, ALT, Alanin amino transferase, TC: Total cholesterol, LDL-C: Low density lipoproteincholesterol, HDL-C: High density lipoprotein- cholesterol, TG: triglyceride, Cr: Creatinine, TC/HDL-C: Total cholesterol/HDL cholesterol, PON1: paraoxonase-1, NS: non-significant.

Results are expressed as mean $\pm S D$. ${ }^{*} p<0.05$ statistically significant

$\mathrm{p}<0.05)$, HDL-C $(\mathrm{r}=0.938, \mathrm{p}<0.05)$ and TC/HDL-C ratio $(r=-0.628, p<0.05)$. We did not find any significant correlation between serum PON1 activities and CIMT values (all $\mathrm{p}>0.05$ ).

\section{Discussion}

A relation between atherosclerosis and chronic H. pylori infection was found in epidemiological studies [17-19]. Pellicano et al. reported significantly higher prevalence of $H$. pylori infection in patients with CAD than in controls $(77 \%$ vs $59 \%)$ [20]. Although these studies have suggested a relationship between $H$. pylori infection and coronary heart disease; some of the underlying mechanisms still need to be discovered. It has been reported that chronic H. pylori infection results in decreased HDL-C levels, and these lipid alterations could, partially contribute to the initiation and development of coronary atherosclerosis $[5,21,22]$. Infection and inflammation are associated with a decrease in HDL-C levels. Induction of changes in lipoproteins by cytokines indirectly predisposes patients to atherosclerosis [23]. In the present study, we did not find any significant difference in TC, HDL-C, LDL-C levels and TC/HDL-C ratios between $H$. pylori positive and negative subjects. However, $H$. pylori positive subjects had significantly higher plasma triglyceride levels than negative subjects. Laurila et al. found significantly increased triglyceride ( $1.17 \mathrm{vs}$ $1.00 \mathrm{mmol} / \mathrm{L}$ ) and total cholesterol $(6.34$ vs $5.87 \mathrm{mmol} /$ L) levels in $460 \mathrm{H}$. pylori positive subjects compared with $269 \mathrm{H}$. pylori negative subjects but HDL-C levels were found to be similar in both groups [24].

Major risk factors of atherosclerosis may explain only $50 \%$ of its etiology. Therefore, looking for new risk factors of atherosclerosis is necessary. HDL-C is a well known parameter inversely related to the risk for CVD. It plays a key role in the reverse cholesterol transport, protects LDL against oxidation and reduces lipoprotein associated peroxides. The antioxidant characteristics of HDL-C have been attributed to PON 1 . In recent years, authors have suggested that low PON1 activity and

Table 3 Structural and functional parameters of vessels for Helicobacter pylori positive and negative subjects

\begin{tabular}{lccc}
\hline Parameter & $\begin{array}{c}\text { H. pylori positive subjects } \\
(\mathbf{n}=\mathbf{3 0})\end{array}$ & $\begin{array}{c}\text { H. pylori negative subjects } \\
(\mathbf{n}=\mathbf{3 1})\end{array}$ & p value \\
\hline Mean Right CIMT $(\mathrm{mm})$ & $0.70 \pm 0.09$ & $0.64 \pm 0.06$ & $<0.05$ \\
\hline Max Right CIMT $(\mathrm{mm})$ & $0,81 \pm 0,10$ & $0.74 \pm 0.07$ & $<0.05$ \\
\hline Mean Left CIMT $(\mathrm{mm})$ & $0.72 \pm 0.14$ & $0.67 \pm 0.08$ & $\mathrm{NS}$ \\
\hline Max Left CIMT $(\mathrm{mm})$ & $0.83 \pm 0.15$ & $0.79 \pm 0.1$ & $\mathrm{NS}$ \\
\hline Mean Overall CIMT $(\mathrm{mm})$ & $0.71 \pm 0.10$ & $0.65 \pm 0.06$ & $<0.05$ \\
\hline Max Overall CIMT $(\mathrm{mm})$ & $0.82 \pm 0.11$ & $0.77 \pm 0.01$ & $<0.05$ \\
\hline Plaque & 3 & 1 & \\
\hline Abbreviations: CIMT: Carotis intima-media thickness, NS: non-significant Results are expressed as mean \pm SD or number of patients
\end{tabular}


concentration were important determinants of the presence of coronary artery disease [25]. Several factors like nutritional, pharmacological, genetic and infectious processes have been demonstrated to modulate PON1 levels [9]. Relationship between PON1 activity and infectious pathogens like HCV and HIV have been shown [26,27]. But, association between $H$. pylori infection and PON1 has been reported in only one study [4]. Aslan et al. found decreased serum PON1 activity in $H$. pylori positive patients [4]. In our study we also observed that serum PON1 activity was significantly lower in $H$. pylori positive subjects when compared with negative subjects.

There is considerable evidence suggesting that ultrasonic measurements of early atherosclerosis are clinically significant. In prospective studies increased IMT has been related to an increased risk of cardiovascular diseases $[28,29]$. There is conflicting data regarding CIMT and $H$. pylori infection. Some researchers have reported no relationship between $H$. pylori and CIMT [23,30,31]. However, Hamed et al. reported significant association between the two in diabetic patients [32]. In our study, the mean and maximum values of right and overall CIMT were significantly increased in $H$. pylori positive subjects compared with negative subjects. The mean and maximum values of left CIMT tended to be higher in $H$. pylori infected subjects but the differences were not significant between the two groups. We determined the correlations between PON1, HDL-C and CIMT respectively. While CIMT was negatively correlated to HDL-C, it showed no correlation with PON1. As is reported by Chen et al., HDL-C is a complex particle populated by multiple proteins that play a critical role in determining the overall effects of the lipoprotein [33]. Our results demonstrate that, PON 1 singularly could not represent the overall antioxidative activity of HDL-C.

The current study has certain limitations. Our study group was limited. We did not perform endoscopy and determine the grade of gastric inflammation or virulence factors of $H$. pylori.

In conclusion; serum PON1 activities were lower in H. pylori positive subjects while right and overall CIMT were significantly higher. Although we found no correlation between CIMT and PON1, these results implied that decreased PON1 activity may have an important role on vascular structural changes induced by $H$. pylori infection. Further studies with larger populations are needed to explore whether there is a strong relationship between PON1 activity and atherosclerosis in $H$. pylori infection.

\footnotetext{
Author details

${ }^{1}$ Akdeniz University Faculty of Medicine, Department of Biochemistry, Antalya, Turkey. ${ }^{2}$ Akdeniz University Faculty of Medicine, Department of Medicine, Antalya, Turkey. ${ }^{3}$ Akdeniz University Faculty of Medicine, Division
}

of Gastroenterology, Antalya Turkey. ${ }^{4}$ Akdeniz University Faculty of Medicine, Department of Cardiology, Antalya - Turkey.

\section{Authors' contributions}

SHA participated in the design of study and performed the biochemical analysis. FD performed the statistical analysis. SB, IS, GS participated in the coordination of study. DK, SK, ID performed CIMT measurements. All authors read and approved the final manuscript.

\section{Competing interests}

The authors declare that they have no competing interests.

Received: 9 July 2010 Accepted: 30 August 2010

Published: 30 August 2010

\section{References}

1. Marshall BJ: The 1995 Albert Lasker Medical Research Award. Helicobacter pylori. The etiologic agent for peptic ulcer. JAMA 1995, 274:1064-6.

2. Parsonnet J, Hansen $S$, Rodriguez $L$, Gelb AB, Warnke RA, Jellum $E_{\text {, }}$ Orentreich N, Vogelman JH, Friedman GD: Helicobacter pylori infection and gastric lymphoma. N Engl J Med 1994, 330:1267-71.

3. Ayada K, Yokota K, Kobayashi K, Shoenfeld Y, Matsuura E, Oguma K: Chronic infections and atherosclerosis. Clin Rev Allergy Immunol 2009, 37(1):44-8

4. Aslan M, Nazligul Y, Horoz M, Bolukbas C, Bolukbas FF: Serum paraoxonase-1 activity in Helicobacter pylori infected subjects. Atherosclerosis 2008, 196:270-274.

5. Jia EZ, Zhao FJ, Hao B, Zhu TB, Wang LS, Chen B, Cao KJ, Huang J, Ma WZ, Yang ZJ, Zhang G: Helicobacter pylori infection is associated with decreased serum levels of high density lipoprotein, but not with the severity of coronary atherosclerosis. Lipids Health Dis 2009, 8:59.

6. Prasad A, Zhu J, Halcox JP, Waclawiw MA, Epstein SE, Quyyumi AA: Predisposition to atherosclerosis by infections: role of endothelial dysfunction. Circulation 2002, 106(2):184-90.

7. Getz GS, Reardon CA: Paraoxonase, a cardioprotective enzyme: continuing issues. Current Opinion in Lipidology 2004, 15(3):261-7.

8. Rozenberg O, Rosenblat M, Coleman R, Shih DM, Aviram M: Paraoxonase (PON1) deficiency is associated with increased macrophage oxidative stress: studies in PON1-knockout mice. Free Radic Biol Med 2003, 34(6):774-84.

9. Gupta N, Gill K, Singh S: Paraoxonases: structure, gene polymorphism \& role in coronary artery disease. Indian J Med Res 2009, 130(4):361-8.

10. Mackness Ml, Durrington PN: HDL, its enzymes and its potential to influence lipid peroxidation. Atherosclerosis 1995, 115(2):243-53.

11. Kiortsis DN, Tsouli S, Lourida ES, Xydis V, Argyropoulou MI, Elisaf M, Tselepis AD: Lack of association between carotid intima-media thickness and PAF-acetylhydrolase mass and activity in patients with primary hyperlipidemia. Angiology 2005, 56(4):451-8.

12. Campo S, Sardo MA, Trimarchi G, Bonaiuto M, Castaldo M, Fontana L, Bonaiuto A, Bitto A, Saitta C, Saitta A: The paraoxonase promoter polymorphism (-107)T $>C$ is not associated with carotid intima-media thickness in Sicilian hypercholesterolemic patients. Clin Biochem 2004, 37(5):388-94

13. Kastelein J, Wiegman A, Groot E: Surrogate markers of atherosclerosis: impact of statins. Atheroscler Supp/ 2003, 4:31-6.

14. Friedewald WT, Levy RI, Fredrickson DS: Estimation of the concentration of low-density lipoprotein cholesterol in plasma, without use of the preparative ultracentrifuge. Clin Chem 1972, 18:499-502.

15. Boers M, Nurmohamed MT, Doelman CJ, Lard LR, Verhoeven AC, Voskuyl AE, Huizinga TW, van de Stadt RJ, Dijkmans BA, van der Linden S: Influence of glucocorticoid and disease activity on total and high density lipoprotein cholesterol in patients with rheumatoid arthritis. Ann Rheum Dis 2003, 62:842-845.

16. MacKness B, Mackness MI, Durrington PN, Arrol S, Evans AE, McMaster D, Ferrières J, Ruidavets JB, Williams NR, Howard AN: Paraoxonase activity in two healthy populations with differing rates of coronary heart disease. Eur J Clin Invest 2000, 30(1):4-10.

17. Mendall M, Goggin P, Molineaux N, Levy J, Toosy T: Relation of Helicobacter pylori infection and coronary heart disease. Br Heart J 1994, 71:437-439. 
18. Danesh J, Collins R, Peto R: Chronic infections and coronary heart disease: is there a link? Lancet 1997, 350:430-436.

19. Glyyn J: Helicobacter pylori and heart. Lancet 1994, 344:146.

20. Pellicano R, Broutet N, Ponzetto A, Megraud F: Helicobacter pylori, from the stomach to the heart. Eur J Gastroenterol-Hepatol 1999, 11:1335-1337.

21. Hoffmeister A, Rothenbacher D, Bode G, Persson K, März W, Nauck MA, Brenner H, Hombach V, Koenig W: Current infection with Helicobacter pylori; but not seropositivity to Chlamydia pneumonia or cytomegalovirus, is associated with atherogenic modified lipid profile. Atheroscler Thromb Vasc Biol 2001, 21:427-432.

22. Danesh J, Peto R: Risk factors for coronary heart disease and infection with Helicobacter pylori; metaanalyses of 18 studies. BMJ 1998, 316:1130.

23. Altintas E, Ucbilek E, Ulu O, Sezgin O, Uzer C: Helicobacter pylori associated atrophic gastritis and carotid intima-media thickness, is there a link? Int Clin Pract 2007, 61(5):810-814.

24. Laurila A, Bloigu A, Näyhä S, Hassi J, Leinonen M, Saikku P: Association of Helicobacter pylori infection with elevated serum lipids. Atherosclerosis 1999, 142:207-210

25. Mackness M, Durrington P, Mackness B: Paraoxonase 1 activity, concentration and genotype in cardiovascular disease. Current Opinion In Lipidology 2004, 15:399-404

26. Ali EM, Shehat HH, Ali-Labib R, Esmail Zahra LM: Oxidant and antioxidant of arylesterase and paraoxonase as biomarkers in patients with Hepatitis C virus. Clinical Biochemistry 2009, 42:1394-1400.

27. Parra S, Alonso-Villaverde C, Coll B, Ferré N, Marsillach J, Aragones G, Mackness M, Mackness B, Masana L, Joven J, Camps J: Serum paraoxonase1 activity and concentration are influenced by human immunodeficiency virus infection atherosclerosis. 2007, 194(1):175-81.

28. O'leary DH, Polak JF, Kronmal RA, Manolio TA, Burke GL, Wolfson SK: Carotid artery intima and media thickness as a risk factor for myocardial infarction and stroke in older adults. New England J Med 1999, 340:14-22.

29. Bots ML, Hoes AW, Kaudsteal PJ, Hofman A, Grobbee DE: Common carotid intima-media thickness and risk of stroke and myocardial infarction. The Rotterdam Study. Circulation 1997, 96:1432-1437.

30. Folsom AR, Nieto FJ, Sorlie P, Chambless LE, Graham DY: For the atherosclerosis risk in communities (ARIC) study investigators; Helicobacter pylori seropositivity and coronary heart disease incidence. Circulation 1998, 98:845-850.

31. Markus HS, Risley P, Mendall MA, Steinmetz H, Sitzer M: Helicobacter pylori infection, the cytotoxin gene a strain, and carotid artery intima-media thickness. J Cardiovasc Risk 2002, 9:1-6.

32. Hamed SA, Amine NF, Galal GM, Helal SR, Tag El-Din LM, Shawky OA, Ahmed EA, Abdel Rahman MS: Vascular risks and complications in diabetes mellitus. the role of Helicobacter pylori infection. J Stroke Cerebrovasc Dis 2008, 17(2):86-94.

33. Chen X, Wu Y, Liu L, Su Y, Peng Y, Jiang L, Liu X, Huang D: Relationship between high density lipoprotein antioxidant activity and carotid arterial intima-media thickness in patients with essential hypertension. Clin Exp Hypertens 2010, 32(1):13-20.

doi:10.1186/1476-511X-9-92

Cite this article as: Akbas et al.: The assessment of carotid intima media thickness and serum Paraoxonase-1 activity in Helicobacter pylori positive subjects. Lipids in Health and Disease 2010 9:92.

\section{Submit your next manuscript to BioMed Central and take full advantage of:}

- Convenient online submission

- Thorough peer review

- No space constraints or color figure charges

- Immediate publication on acceptance

- Inclusion in PubMed, CAS, Scopus and Google Scholar

- Research which is freely available for redistribution

Submit your manuscript at www.biomedcentral.com/submit
Biomed Central 